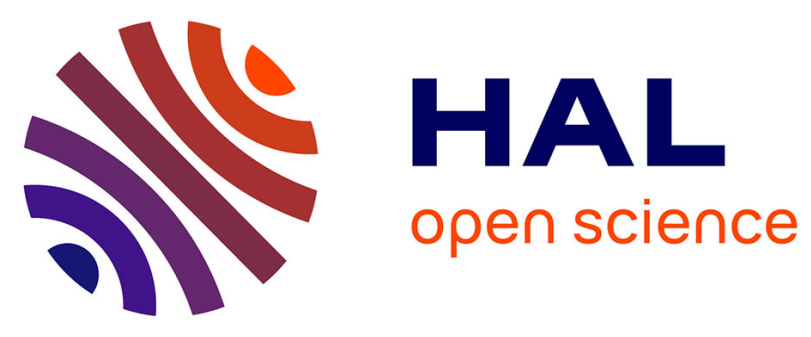

\title{
Intratemporal facial nerve schwannoma: clinical presentation and management
}

Ghizlene Lahlou, Yann Nguyen, Francesca Yoshie Russo, Evelyne Ferrary, Olivier Sterkers, Daniele Bernardeschi

\section{- To cite this version:}

Ghizlene Lahlou, Yann Nguyen, Francesca Yoshie Russo, Evelyne Ferrary, Olivier Sterkers, et al.. Intratemporal facial nerve schwannoma: clinical presentation and management. European Archives of Oto-Rhino-Laryngology, 2015, 273 (11), pp.3497-3504. 10.1007/s00405-015-3850-z . hal-01255068

\section{HAL Id: hal-01255068 https: / hal.sorbonne-universite.fr/hal-01255068}

Submitted on 13 Jan 2016

HAL is a multi-disciplinary open access archive for the deposit and dissemination of scientific research documents, whether they are published or not. The documents may come from teaching and research institutions in France or abroad, or from public or private research centers.
L'archive ouverte pluridisciplinaire HAL, est destinée au dépôt et à la diffusion de documents scientifiques de niveau recherche, publiés ou non, émanant des établissements d'enseignement et de recherche français ou étrangers, des laboratoires publics ou privés. 


\section{INTRATEMPORAL FACIAL NERVE SCHWANNOMA: CLINICAL PRESENTATION AND MANAGEMENT}

Ghizlene Lahlou ${ }^{1,2,3}$, Yann Nguyen ${ }^{1,2,3}$, Francesca Yoshie Russo ${ }^{1,2,3}$, Evelyne Ferrary ${ }^{1,2,3}$, Olivier Sterkers $^{1,2,3}$ and Daniele Bernardeschi ${ }^{1,2,3}$

1. AP-HP, Pitié-Salpêtrière Hospital, Department of Otology Auditory Implants and Skull Base Surgery. Paris, France

2. Sorbonne Universités, UPMC University Paris 6. 75005, Paris, France

3. Inserm UMR-S 1159, «Mini-invasive and robot-based surgical rehabilitation of hearing », 75005, Paris, France

\section{Corresponding author:}

Daniele Bernardeschi, MD, PhD

Department of Otology, Auditory Implants and Skull Base Surgery

Pitié-Salpêtrière Hospital

50/52 Bd Vincent Auriol

75013 - Paris - France

Tel: +33(0)142162603

Fax : + $33(0) 142162605$

E-mail : daniele.bernardeschi@aphp.fr

Authors do not have any conflict of interest or financial disclosure to declare 


\section{ABSTRACT}

Facial nerve schwannoma is the most common facial nerve tumor, but its therapeutic strategy remains debated. The aim of this study is to analyse the facial nerve function and the hearing outcomes after surgery or wait-and-scan policy in a facial nerve schwannoma series. A monocentric retrospective review of medical charts of patients followed for an intratemporal facial nerve schwannoma between 1988 and 2013 was performed. Twenty-two patients were included. Data was extracted pertaining to the following variables: patient demographics; tumor localization; clinical and imaging features; facial nerve function and hearing levels; details of surgical intervention. The majority of tumors were located at the geniculate ganglion. Initial symptoms were mainly facial palsy and hearing loss. The average follow-up was $4.8 \pm 4.5$ years. Nineteen patients underwent surgery, and 3 patients were observed. After surgery, 11 patients had a stable or improved FN function $(57.9 \%)$, and 8 patients had a worsened FN function (42.1\%). Facial nerve function was in the majority of cases a HB grade III, depending on surgical strategy. No patient presented a postoperative HB grade V or VI. Regarding the hearing, it remained stable after surgery in $52.6 \%$ of cases, and improved in $10.5 \%$ of cases. Among monitored patients, facial nerve function and hearing remained stable. Surgery for facial nerve schwannoma is a safe and effective option in the treatment of these tumors.

Keywords: Facial; Schwannoma; Intratemporal; Hearing; Graft 


\section{INTRODUCTION}

Facial nerve schwannoma (FNS), although rare, is the most common tumor of the facial nerve (FN). It is a benign encapsulated slow growing lesion arising from the Schwann cells of the FN. In an anatomical study of 600 temporal bones, an intratemporal sporadic FNS was found in less than $1 \%$ [1]. It is more frequent in case of neurofibromatosis type 2, with an incidence of 58\% [2]. It can involve any of the different segments of the FN, and most of the time, it involves more than one segment, with a predilection for the geniculate ganglion and the tympanic portion $[3,4]$.

FNS is more often revealed by a progressive facial weakness, however, in case of a sudden onset of the facial impairment it can be wrongly diagnosed as idiopathic facial paralysis [5]. Other symptoms might be present such as sensorineural or conductive hearing loss, tinnitus, otalgia, and vestibular dysfunction, depending on its location among the intratemporal FN course [5].

The management of the FNS is challenging. Wait-and-scan policy could be a viable option in case of normal facial function and no compression on the brainstem. The surgical management encompasses several techniques. The total resection with FN graft or end-to-end anastomosis results on a variable permanent deficit $[3,6]$, but still remains the more common surgical choice. The entire excision of the tumor with anatomical preservation of the FN is possible in very few favourable cases [7]. Other surgical options are FN decompression or subtotal resection of the tumor [8]. More recently, radiosurgery has been used to treat FNS, with satisfying results on the stabilisation of tumour's size [9-17].

The aim of this retrospective study is to describe the clinical presentation of FNS, to report the FN function and hearing outcomes in FNS surgery and surveillance, in order to define the prognostic factors of the postoperative $\mathrm{FN}$ function. 


\section{MATERIALS AND METHODS}

The medical charts of patients managed for FNS from 1988 to 2013 in a tertiary referral centre were retrospectively reviewed. The other facial nerve tumors (haemangioma, meningioma) were excluded, as well as the extra-cranial FNS. Because neurofibromatosis type 2 is a complex disease with a risk of multiple tumors and multifactorial symptoms, patients with a diagnosis of neurofibromatosis type 2 presenting a FNS were also excluded. Overall, 22 patients were included in the study. All patients gave their informed consent for the use of their clinical data.

All the patients were evaluated and operated by the same senior surgeon (OS).

The data collected at the first visit included demographics, onset symptoms, facial function according to the House and Brackman (HB) scale [18], hearing class according to the AAOHNS hearing classification system [19], mean pure tone audiometry (PTA) (mean of $500,1000,2000$ and $3000 \mathrm{~Hz}$ ) in bone and air conduction with headphone, and the vestibular function evaluated by a caloric test. Imaging (high resolution computed tomography and magnetic resonance imaging) was analysed to classify tumor location in relation to the geniculate ganglion (GG) (figure 1); tumors located in the geniculate ganglion (GG) and medial to it (cerebello-pontine angle, internal auditory canal and labyrinthine segment); tumors located exclusively in the GG; and tumors in the GG and lateral to it (tympanic and mastoid segment). Imaging was also analysed to detect complications (external auditory canal erosion, ossicular displacement, labyrinthine fistula or brainstem compression).

For patients who underwent surgery, perioperative data included surgical approach and reconstruction of the FN. Postoperative outcomes included FN and auditory function, and post-operative complications. The patients underwent a control at 6 months, one year, two years postoperatively, and then once every three years. 
For patients who underwent wait-and-scan management, the FN function was monitored, as well as the hearing and the tumor growth during the same follow-up intervals.

Results are presented as mean \pm SD. Fisher exact test and Student t-test were performed, to compare preoperative and postoperative PTA, and to explore the results over the follow-up as appropriated. A p $<0.05$ was considered as significant. For the postoperative data, statistical tests were performed at 12 months postoperatively. 


\section{RESULTS}

\section{Population}

Twenty-two patients were included in this study: patients' characteristics are summarized in table 1 . Of the 22 patients, 19 underwent surgery and 3 were treated conservatively.

\section{Tumor location}

There were 7 tumors with a medial extension to GG (31.7\%), 6 tumors located only in the GG (27.3\%), and 9 tumors with a lateral extension to GG (40.8\%).

Overall, the GG was affected in 18 cases $(81.8 \%)$, with an extension to the adjacent segments in half of the cases $(54.8 \%)$. No patient in this series presented an extension both proximally and distally to the GG. In 12 cases (54.5\%) the tumor extended over two or more segments of the FN.

\section{Clinical presentation}

The presenting symptoms at first visit were the following: facial paralysis (11 patients, 50\%), hearing loss (6 patients, 27.3\%), dizziness (4 patients, 18.2\%), unilateral tinnitus (4 patients, $18.2 \%$ ), and otalgia (2 patients, $9.1 \%$ ). Five patients presented with more than one symptom at the first visit.

\section{Facial nerve}

The facial function at the time of the first visit was HB grade I in 5 patients $(22.7 \%)$, HB grade II in 6 patients $(27.3 \%)$, HB grade III in 2 patients $(9.1 \%)$, HB grade IV in 4 patients (18.2\%), HB grade V in 4 patients (18.2\%) and HB grade VI in one patient (4.5\%).

The facial paralysis had a variable clinical presentation. Among the 17 patients with facial paralysis a progressively worsening paralysis was present in 11 patients (64.7\%), a sudden onset was reported in 4 cases $(23.5 \%)$, and recurrent episodes of sudden onset with spontaneous partial improvement in 2 patients $(11.8 \%)$. The location of the FNS did not influence the onset and progression of the facial palsy (Fisher test). 


\section{Hearing}

The mean PTA was $45 \pm 36 \mathrm{~dB}$. Class A hearing was found in 9 patients (40.9\%), a class B hearing in 4 patients, (18.2\%), a class $\mathrm{C}$ hearing in 4 patients $(18.2 \%)$, and a class D hearing in 5 patients $(22.7 \%$ ) (Table 2). Among patients who had hearing loss, sensorineural hearing loss was present for all the tumors located medially to GG (4 cases, 100\%). For tumors located in the GG and lateral to the GG, there was conductive hearing loss in 3 cases $(33.3 \%)$, mixed hearing loss in 3 cases (33.3\%), and sensorineural hearing loss in 3 cases $(33.3 \%)$. Five patients $(22,7 \%)$ had a cochlear fistula at the basal turn, diagnosed by computed tomography. Three of them had a class D hearing and two a class C.

\section{Other symptoms}

Nine patients $(40.9 \%)$ had tinnitus. Two patients $(9.1 \%)$ presented otalgia as the onset symptom.

Six of the 22 patients were not tested for vestibular function. For the remaining 16 patients, vestibular impairment was found in 12 cases $(75 \%)$ with ipsilateral vestibular areflexia or hyporeflexia at the caloric test. No significant correlation was found between the tumor location and the vestibular impairment (Fisher's test).

\section{Evolution of monitored patients}

Three patients (13.6\%) underwent a follow-up observing the facial function grade, the tumor's size, the non-invalidating symptoms, and the age. The average follow-up (FU) was $10.1 \pm 5.2$ years (range 4.7 - 15 years). One patient had facial function grade I HB, one a HB grade II, and one patient a HB grade VI. The first 2 patients showed no decline in facial function or in hearing during follow-up. No surgery was proposed for third patient because of the advanced age and the presence of a severe facial palsy lasting for 25 years before the diagnosis. 
As far as the tumor size was concerned, it remained stable in 2 cases during the follow-up. One patient affected by a FNS involving the GG, the IAC and the CPA with a normal facial function had an increase in tumor size, with a growth rate of $0.96 \mathrm{~mm} / \mathrm{year}$ initially, then $1.8 \mathrm{~mm} /$ year after 14 years, then $6 \mathrm{~mm} /$ year after 15 years.

Evolution of surgically treated patients: surgical approach and intraoperative findings

Nineteen out of 22 patients $(86.4 \%)$ underwent surgery. The average postoperative follow-up was $4.2 \pm 3.5$ years (range $1-12.4$ years). Surgical approach was middle cranial fossa (MCF) in 11 cases (57.9\%), transmastoid (TM) in 3 cases (15.8\%), a combined MCF / TM in 2 cases (10.5\%), transcochlear in 2 cases $(10.5 \%)$, and a translabyrinthine in one case $(5.3 \%)$.

In all but 2 patients a total removal of the tumor was performed. One patient had tumor decompression, and one patient had partial excision. Both of them were affected by a FNS involving the mastoid portion of the facial nerve.

In the 17 remaining patients $(89.5 \%)$, a total tumor removal was achieved. An anatomical preservation of the $\mathrm{FN}$ at the end of the procedure was obtained in 2 cases $(10.5 \%)$.

In the other 15 patients (79\%), the FN was interrupted during the resection. The FN reconstruction was achieved with a great auricular nerve graft in 10 patients $(52.6 \%)$ and with a sural nerve graft in 3 patients $(15.7 \%)$, using only fibrin glue and no sutures for the anastomosis [20]. In 2 patients (10.5\%), an end-to-end anastomosis with FN rerouting was performed.

Regarding the ossicular chain, an ossicular reconstruction was performed in two cases.

No major complication was observed post-operatively (intracranial hematoma, cerebrospinal fluid leak, meningitis, death). There was one case of subcutaneous abdominal hematoma (5.3\%). A tumor recurrence 11 years after the surgery was seen in one case $(5.3 \%)$ after excision with an anatomical intact FN. 
Evolution of surgically treated patients: FN function

Facial nerve function at the last postoperative follow-up was HB grade I in one case (5.3\%), HB grade II in 2 cases (10.5\%), HB grade III in 12 cases (63.2\%), and HB grade IV in 4 cases (21.1\%). No patient had severe facial nerve palsy (HB grade V or grade VI). Table 3 shows the postoperative facial nerve function depending on the technique of facial rehabilitation.

There was no prognostic factor found in this study for the postoperative facial function. There was no significant difference depending on the patient's age (Student's test), the tumour location (Fisher's test), the number of affected segments of the facial nerve (Fisher's test), the duration of the preoperative paralysis (Student's test), or the preoperative facial function (Fisher's test).

After surgery, 11 patients had a stabilized or improved FN function (57.9\%), and 8 patients had a declined FN function (42.1\%). For all these 8 patients, preoperative FN function was HB grade II or less. In one case of declined FN function, the diagnosis of FNS was made intra-operatively (tumor of the IAC and CPA). In the other 7 cases, the surgery was decided because of disabling vertigo in 4 cases, and because of the tumor size in 3 cases.

Evolution of surgically treated patients: hearing

Postoperatively, mean PTA was $57.4 \pm 44.6 \mathrm{~dB}$. The hearing remained unchanged in 10 patients $(52.6 \%)$. It was improved in 2 patients $(10.5 \%)$ who had a preoperative conductive hearing loss treated with ossicular chain reconstruction. 


\section{DISCUSSION}

FNS is an uncommon tumor that can be difficult to diagnose and manage. The tumor can be located in any segment of the facial nerve and is often located in more than one segment. In this study, the most frequent location was the geniculate ganglion, such as described in the literature [21]. Other studies report FNS located both medial and lateral to GG, even in all FN portion [22-25]. FN function seems to not be related to the tumor location, neither the grade, nor the evolution of facial palsy. Regarding the initial hearing, type of hearing depends on the tumor location, as previously described in an anatomo-clinical classification [5].

To date, the therapeutic strategy for FNS is depends on facial function, tumour size and its evolution, hearing, and others disabling symptoms (dizziness, intra-cerebral and brainstem compressions). As far as the FNSs are slow-growing lesions, observation based on serial clinical examination and imaging is one valid option. The growth rate has been reported to be between 0.85 and $1.4 \mathrm{~mm}$ per year [6,10]. In this study, among the patients managed with a wait-and-scan policy, there was no decline in the facial function or hearing, but one patient had a significant increase of the tumor size (up to $6 \mathrm{~mm}$ per year). Wilkinson et al. [10] reported 15 monitored patients, of which one spontaneously improved his facial function, and the others were stable. The hearing has not changed [10]. Perez et al. presented 13 monitored patients [6]. Five worsened their facial function over periods of evolution from 3 to 7 years, and 4 of them had a tumor size growth [6].

If a surgical treatment is chosen, the surgical approach depends on the tumor location and preoperative hearing. The surgery can allow a hearing improvement in case of conductive hearing loss if an ossicular chain reconstruction is combined with the tumor resection. Tumor excision with facial nerve grafting is indicated if the facial function is HB grade III or more. This technique allows a complete resection, with a low risk of recurrence. In this study, the postoperative final facial function is HB grade III in most cases, as described in the literature 
[10,21-23]. No graft failure was observed. Thus, this is a reliable and repeatable technique that allows a HB grade III facial function postoperatively in most of cases.

If an end-to-end anastomosis is possible, the evolution is rather similar to the facial nerve graft. No statistical difference has been found between end to end anastomosis and graft for facial outcome.

If possible, a total tumor resection with dissection of the facial nerve (stripping) might be the choice for patients with a good facial function that undergo surgery for other disabling symptoms. In this study, one patient worsened his facial function from I to II, and another improved it from IV to III. Literature reports also cases of worsened facial function after stripping. Indeed, Lee et al. reported 6 patients operated-on with facial nerve stripping, of which 4 stable facial function and two aggravated [26]. Perez et al. showed 3 cases of decline, two cases of improvement, and two cases of stabilisation [6]. This technique appears to be a satisfactory solution, but with postoperative outcomes difficult to predict, and the risk to leave a part of the tumor on the FN. The only case of recurrence in our series was a patient that underwent a stripping technique. Therefore, a total resection with facial nerve graft that allows a postoperative $\mathrm{HB}$ grade III in most of the cases, should be preferred if the preoperative facial function is worst than a HB grade II.

An alternative technique is the subtotal excision of the tumor, which attempts a preservation of the facial nerve. This procedure should be recommended in case of large tumour compressing the brainstem with good facial function [23]. McRackan et al showed statistically decreased risk of having postoperative severe facial palsy (HB grade IV or more) [25], but even if the nerve anatomy is intact, this does not guarantee the preservation of facial function. It also requires a prolonged postoperative MRI surveillance. Li et al showed a high recurrence rate after subtotal excision, which was $26.6 \%$ in general, and $60 \%$ if only $70-80 \%$ of the tumor was removed [27]. 
Lastly, a decompression of the facial nerve could be an option. Wilkinson et al [10] described 21 cases who underwent decompression of the facial nerve: $78.9 \%$ of patients maintained stable or improved their facial function while only $5.3 \%$ of patients worsened their facial function. In our study, one patient underwent this technique, with a stable facial function after surgery.

The table 4 shows facial outcomes in the literature after surgery depending on surgical technique, the results emerging from the present study are similar to those of other reports. In this study, after surgical excision of intrapetrous FNS, the facial function is improved or stabilized in most of the cases. For patients who had a decrease of the facial function after surgery, the indication of surgery was for tumor size growth, invaliding dizziness or misdiagnosis with the more common vestibular schwannoma. As a matter of fact, FNS is diagnosed intraoperatively in $3.2 \%$ of cases [28].

Radiosurgery is an alternative to surgery. The indication is given most often based on the tumor size. In the literature a total of 85 cases have been managed with radiosurgery (Table 5) [9-15,17,29]. After treatment, the facial function is generally stable, but 11 cases of function decline are described in the literature, regardless of pre-treatment FN function $[9,15,17]$. Tumor size tends to remain stable or to decrease in the majority of cases, but 4 cases of increased size after treatment were reported [10,11,15,17]. A case of cystic transformation has been described after radiosurgery with an increase in size and complete facial paralysis of acute onset [15]. A meta-analysis regarding 45 patients who underwent radiosurgery for FNS shows a tumor control in $93,3 \%$ of cases with a mean follow-up of 42,1 months [16]. In this meta-analysis, facial function was stable in $66,7 \%$ of cases, worsened in $12,8 \%$, and improved in $20,5 \%$. Radiosurgery was performed in the majority of cases because of tumor growth. Hasegawa et al [29], found a statistically significant association between tumor growth and development of facial palsy after radiosurgery. In this study, FN function decline is found in 
case of a preoperative HB grade I or II (with one case of HB grade IV postoperatively), and improvement in case of $\mathrm{HB}$ grade III, IV or V. These results need to be compared to the natural history of the FN function in FNS, which can remain stable in a long observational period. Furthermore, some degree of hearing deterioration can occur after radiosurgery [29]. Considering the results of the present study and the emerging evidences of the literature, a flow-chart for the management of FNS can be proposed (Figure 1).

\section{CONCLUSION}

FNS is a rare benign lesion that can be successfully treated surgically when symptomatic, and when a moderate to severe facial palsy is present. Gamma knife could be a viable option in case of growing tumors with good facial function. 


\section{REFERENCES}

1. Saito H, Baxter A. Undiagnosed intratemporal facial nerve neurilemomas. Arch Otolaryngol. 1972;95:415-419.

2. Nam S-I, Linthicul FH, Merchant SN. temporal bone histopathology in neurofibromatosis type 2. Laryngoscope. 2011;121:1548-1554.

3. McMonagle B, Al-Sanosi A, Croxson G, Fagan P. Facial schwannoma: results of a large case series and review. J Laryngol Otol. 2008;122:1139-1150.

4. Thompson AL, Aviv RI, Chen JM, et al. Magnetic resonance imaging of facial nerve schwannoma. Laryngoscope. 2009;119:2428-2436.

5. Sterkers O, Viala P, Rivière F, Sterkers J. Neurinoma of the intratemporal facial nerve. Anatomo-clinical classification of 12 cases. Ann Otolaryngol Chir Cervicofac. 1986;103:501-508.

6. Perez R, Chen JM, Nedzelski JM. Intratemporal facial nerve schwannoma: a management dilemma. Otol Neurotol. 2005;26:121-126.

7. Lee W, Kim J. Revised surgical strategy to preserve facial nerve function after resection of the facial nerve schwannoma. Otol Neurotol. 2011;32:1548-1553.

8. Angeli SI, Brackmann DE, Angeles L. Is surgical excision of facial nerve schwannomas always indicated ? Otolaryngol Head Neck Surg. 1997;117:144-147.

9. Kida Y, Yoshimoto M, Hasegawa T. Radiosurgery for Facial Schwannoma. Journal of neurosurgery. 2007;106:24-29.

10. Wilkinson E, Hoa M, Slattery W 3rd, et al. Evolution in the management of facial nerve schwannoma. Laryngoscope. 2011;121:2065-2074.

11. Litre CF, Gourg GP, Tamura M, et al. Gamma knife surgery for facial nerve schwannomas. Neurosurgery. 2007;60:853-858. 
12. Nishioka K, Abo D, Aoyama H, et al. Stereotactic Radiotherapy for Intracranial Nonacoustic Schwannomas Including Facial Nerve Schwannoma. Int J Radiat Oncol Biol Phys. 2009;75:1415-1419.

13. Madhok R, Kondziolka D, Flickinger JC, Lunsford LD. Gamma knife radiosurgery for facial schwannomas. Neurosurgery. 2009;64:1102-1105.

14. Hillman T, Chen D, Fuhrer R. An alternative treatment for facial nerve tumors: shortterm results of radiotherapy. Ear Nose Throat J. 2008;87:574-577.

15. Jacob J, Driscoll C, Link M. Facial nerve schwannomas of the Cerebellopontine Angle: The Mayo Clinic Experience. J Neurol Surg B Skull Base. 2012;73:230-235.

16. McRackan T, Wilkinson E, Brackmann D, Slattery W 3rd. Stereotactic Radiosurgery for Facial Nerve Schwannomas: Meta-analysis and Clinical Review. Otol Neurotol. 2015;36:393-398.

17. Moon J, Chang W, Jung H, Lee K, Park Y, Chang J. Gamma knife surgery for facial nerve schwannomas. J Neurosurg. 2014;121:116-122.

18. House J, Brackmann D. Facial nerve grading system. Otolaryngol Head Neck surg. 1985;93:146-147.

19. American Academy of Otolaryngology-Head and Neck Surgery Foundation. Committee on Hearing and Equilibrium guidelines for the evaluation of hearing preservation in acoustic neuroma (vestibular schwannoma). Otolaryngol Head Neck Surg. 1995;113:179-180.

20. Bozorg Grayeli A, Mosnier I, Julien N, El Garem H, Bouccara D, Sterkers O. Longterm functional outcome in facial nerve graft by fibrin glue in the temporal bone and cerebellopontine angle. Eur Arch Otorhinolaryngol. 2005;262:404-407.

21. Sherman J, Dagnew E, Pensak M, van Loveren H, Tew J. Facial Nerve Neuromas : Report of 10 Cases and Review of the Literature. Neurosurgery. 2002;50:450-456.

22. Chung J, Ahn J, Kim J, Nam S, Kim C, Lee K. Facial Nerve Schwannomas : Different Manifestations and Outcomes. Surg Neurol. 2004;62:245-252. 
23. Bacciu A, Nusier A, Lauda L, Falcioni M, Russo A, Sanna M. Are the Current Treatment Strategies for Facial Nerve Schwannoma Appropriate Also for Complex Cases? Audiol Neurotol. 2013;18:184-191.

24. Doshi J, Heyes R, Freeman SRM, et al. Clinical and Radiological Guidance in Managing Facial Nerve Schwannomas. Otol Neurotol. 2015;36:892-895.

25. McRackan T, Rivas A, Wanna G. Facial nerve outcomes in facial nerve schwannomas. Otol Neurotol. 2012;33:78-82.

26. Lee JD, Kim SH, Song MH, Lee H-K, Wong-Sang L. Management of facial Nerve Schwannoma in Patients With Favorable Facial Function. Laryngoscope. 2007;117:1063-1068.

27. Li Y, Liu H, Cheng Y. Subtotal resection of facial nerve schwannoma is not safe in the long run. Acta Otolaryngol. 2014;134:433-436.

28. Lee JD, Lee W-S. Surgical findings to differentiate between facial nerve schwannoma and vestibular schwannoma. Clin Exp Otorhinolaryngol. 2014;7:157-159.

29. Hasegawa T, Kato T, Kida Y, et al. Gamma Knife: surgery for patients with facial nerve schwnnomas: a multiinstitutional retrospective study in Japan. J Neurosurg. 2015;11:1-8.

30. Biswas D, Marnane CN, Orl-hns F, Mal RK, Baldwin DL. The presenting features of middle ear facial nerve sheath tumors: a clinical review. Am J Otolaryngol. 2008;29:58-62.

31. Mowry S, Hansen M, Gantz B. Surgical management of internal auditory canal and cerebellopontine angle facial nerve schwannoma. Otol Neurotol. 2012;33:1071-1076.

32. Bacciu A, Medina M, Ben Ammar M, et al. Intraoperatively diagnosed cerebellopontine angle facial nerve schwannoma: how to deal with it. Ann Otol Rhinol Laryngol. 2014;123:647-653. 
Fig1 Management strategy for facial nerve schwannoma. GKS = Gamma Knife Surgery

Fig2 Imaging of FNS in various localization in respect to the GG. a: isolated GG facial nerve schwannoma. b: FNS involving the GG, IAC and CPA. c: FNS of the mastoid portion of the FN.

Table 1. Demographic characteristics and medical history

\begin{tabular}{ll}
\hline SEX & $\mathrm{N}=22$ \\
Men & $9(41 \%)$ \\
Women & $13(59 \%)$ \\
AGE (year) & $50 \pm 15.6$ \\
SIDE & \\
Right & 13 \\
Left & 8 \\
MEDICAL HISTORY & \\
Malignant tumor & 2 (thyroïd and breast) \\
Cerebral tumor & 2 (meningiomas) \\
Other schwannoma & 1 (arm schwannoma) \\
\hline
\end{tabular}


Table 2 . Hearing depending on tumor location.

$G G=$ geniculate ganglion; Medial to $G G=$ Locations between the cerebello-pontine angle and the GG; Lateral to $G G=$ Locations between $G G$ and mastoid segment; $S N H L=$ sensorineural hearing loss; $M H L=$ mixed hearing loss; $\mathrm{CHL}=$ conductive hearing loss

\begin{tabular}{l|llll}
\hline & $G G(n=6)$ & $\begin{array}{l}\text { Medial } \\
\text { to } G G(n=7)\end{array}$ & $\begin{array}{l}\text { Lateral } \\
\text { to } G G(n=9)\end{array}$ & Total $(n=22)$ \\
\hline Hearing classification & & 3 & 3 & 9 \\
Class A & 3 & 0 & 3 & 4 \\
Class B & 1 & 1 & 2 & 4 \\
Class C & 1 & 3 & 1 & 5 \\
Class D & 1 & & 2 & 7 \\
\hline Type of hearing loss & & 4 & 2 & 3 \\
SNHL & 1 & 0 & 2 & 3 \\
MHL & 1 & 0 & & \\
CHL & 1 & &
\end{tabular}


Table. 3. Facial nerve function after surgery and wait-and scan

\begin{tabular}{|c|c|c|c|c|c|c|c|c|c|c|c|c|}
\hline \multirow[b]{2}{*}{ Grade I, II, III } & \multicolumn{2}{|c|}{$\begin{array}{c}\text { Facial nerve } \\
\text { grafting }\end{array}$} & \multicolumn{2}{|c|}{$\begin{array}{l}\text { End-to-end } \\
\text { anastomosis }\end{array}$} & \multicolumn{2}{|c|}{ Dissection } & \multicolumn{2}{|c|}{ Decompression } & \multicolumn{2}{|c|}{$\begin{array}{l}\text { Partial } \\
\text { excision }\end{array}$} & \multicolumn{2}{|c|}{ Observation } \\
\hline & 8 & $77 \%$ & 1 & $50 \%$ & 2 & $100 \%$ & 1 & $100 \%$ & 1 & $100 \%$ & 2 & $67 \%$ \\
\hline Grade IV, V, VI & 3 & $23 \%$ & 1 & $50 \%$ & 0 & $0 \%$ & 0 & $0 \%$ & 0 & $0 \%$ & 1 & $33 \%$ \\
\hline Improved & 5 & $38 \%$ & 0 & $0 \%$ & 1 & $50 \%$ & 0 & $0 \%$ & 0 & $0 \%$ & 0 & $0 \%$ \\
\hline Stable & 3 & $23 \%$ & 0 & $0 \%$ & 0 & $0 \%$ & 1 & $100 \%$ & 1 & $100 \%$ & 3 & $100 \%$ \\
\hline Decreased & 5 & $38 \%$ & 2 & $100 \%$ & 1 & $50 \%$ & 0 & $0 \%$ & 0 & $0 \%$ & 0 & $0 \%$ \\
\hline Total & 13 & $100 \%$ & 2 & $100 \%$ & 2 & $100 \%$ & 1 & $100 \%$ & 1 & $100 \%$ & 3 & $100 \%$ \\
\hline
\end{tabular}


Table 4. Postoperative facial function after surgery in literature.

\begin{tabular}{|c|c|c|c|c|c|c|c|c|c|}
\hline & \multicolumn{2}{|c|}{ Facial nerve grafting } & \multicolumn{2}{|c|}{ Dissection } & \multicolumn{2}{|c|}{ Decompression } & \multicolumn{2}{|c|}{ Partial excision } & \multirow[t]{2}{*}{$\mathbf{N}$} \\
\hline & $\mathrm{N}$ & Results & $\mathrm{N}$ & Results & $\mathrm{N}$ & Results & $\mathrm{N}$ & Results & \\
\hline Angeli et al., $1997^{8}$ & & & & & 2 & $\begin{array}{l}\text { I (50\%) } \\
\text { II (50\%) }\end{array}$ & & & 2 \\
\hline Sherman et al., 2002 ${ }^{21}$ & 5 & III $(80 \%)$ & 2 & $\begin{array}{l}\text { I (50\%) } \\
\text { II (50\%) }\end{array}$ & & & & & 7 \\
\hline Chung et al., 2004 22 & 2 & III $(100 \%)$ & & & & & & & 2 \\
\hline Perez et al., $2005^{6}$ & & & 5 & $\begin{array}{l}\text { I (29\%) } \\
\text { II }(14 \%) \\
\text { III }(57 \%)\end{array}$ & & & & & 5 \\
\hline Lee et al., $2007^{26}$ & & & 6 & $\begin{array}{l}\text { I (33\%) } \\
\text { II }(67 \%)\end{array}$ & & & & & 6 \\
\hline Biswas et al., 2008 ${ }^{30}$ & 4 & $\begin{array}{l}\text { III (25\%) } \\
\text { IV (75\%) }\end{array}$ & & & & & & & 4 \\
\hline Wilkinson et al., $2011^{10}$ & 37 & $\begin{array}{l}\text { III (55\%) } \\
\text { IV (29\%) }\end{array}$ & & & 21 & $\begin{array}{l}\text { I }(58 \%) \\
\text { II }(32 \%) \\
\text { III }(10,5 \%)\end{array}$ & & & 58 \\
\hline Mowry et al., $2012^{31}$ & 1 & III (100\%) & & & 2 & I (100\%) & 10 & $\begin{array}{l}\text { I }(60 \%) \\
\text { II }(30 \%) \\
\text { III }(10 \%)\end{array}$ & 13 \\
\hline Bacciu et al., $2013{ }^{23}$ & 9 & $\begin{array}{l}\text { III }(67 \%) \\
\text { IV }(22 \%) \\
\text { VI }(11 \%)\end{array}$ & & & & & 1 & III $(100 \%)$ & 10 \\
\hline Li et al., $2014{ }^{27}$ & & & & & & & 15 & $\begin{array}{l}\text { I }(33,3 \%) \\
\text { II }(60 \%) \\
\text { III }(6,7 \%)\end{array}$ & 15 \\
\hline Bacciu et al., $2014^{32}$ & 7 & $\begin{array}{l}\text { III (86\%) } \\
\text { I (14\%) }\end{array}$ & 3 & $\begin{array}{l}\text { I (33\%) } \\
\text { II }(33 \%) \\
\text { III }(33 \%)\end{array}$ & 4 & $\mathrm{I}(100 \%)$ & 6 & $\begin{array}{l}\text { I (83\%) } \\
\text { II (17\%) }\end{array}$ & 20 \\
\hline Doshi et al., $2015^{24}$ & 9 & $\begin{array}{l}\text { III (33\%) } \\
\text { IV (44\%) } \\
\text { V-VI }(22 \%)\end{array}$ & & & 1 & I $(100 \%)$ & & & 10 \\
\hline Present study & 15 & $\begin{array}{l}\text { III (73\%) } \\
\text { IV }(27 \%)\end{array}$ & 2 & $\begin{array}{l}\text { II (50\%) } \\
\text { III }(50 \%)\end{array}$ & 1 & $\mathrm{I}(100 \%)$ & 1 & I (100\%) & 19 \\
\hline
\end{tabular}


Table 5. Review of results after radiosurgery in the literature

\begin{tabular}{|c|c|c|c|c|c|c|c|c|}
\hline \multirow[t]{2}{*}{ Study } & \multirow[t]{2}{*}{$\mathbf{N}$} & \multirow{2}{*}{$\begin{array}{l}\text { Dose (Gy) } \\
(\text { min-max) }\end{array}$} & \multicolumn{3}{|c|}{ Facial function } & \multicolumn{3}{|l|}{ Tumor size } \\
\hline & & & Improved & Stable & Worsened & Reduced & Stable & Progression \\
\hline $\begin{array}{l}\text { Kida et al., } \\
2007^{9}\end{array}$ & 14 & $11-16$ & $5(36 \%)$ & $8(57 \%)$ & $1(7 \%)$ & $8(57 \%)$ & $6(43 \%)$ & $0(0 \%)$ \\
\hline $\begin{array}{l}\text { Litre et al., } \\
2008^{11}\end{array}$ & 11 & $10-16$ & $3(27 \%)$ & $8(73 \%)$ & $0(0 \%)$ & $4(36 \%)$ & $6(56 \%)$ & $1(9 \%)$ \\
\hline $\begin{array}{l}\text { Hillman et } \\
\text { al, } 20088^{14}\end{array}$ & 2 & 12 & $1(50 \%)$ & $1(50 \%)$ & $0(0 \%)$ & $0(0 \%)$ & $2(100 \%)$ & $0(0 \%)$ \\
\hline $\begin{array}{l}\text { Nishioka et } \\
\text { al., } 20099^{12}\end{array}$ & 4 & 50 for all & $0(0 \%)$ & $\begin{array}{l}4 \\
(100 \%)\end{array}$ & $0(0 \%)$ & $2(50 \%)$ & $2(50 \%)$ & $0(0 \%)$ \\
\hline $\begin{array}{l}\text { Madhok et } \\
\text { al, 2009 }{ }^{13}\end{array}$ & 6 & $12-12.5$ & $1(17 \%)$ & $5(83 \%)$ & $0(0 \%)$ & $3(50 \%)$ & $3(50 \%$ & $0(0 \%)$ \\
\hline $\begin{array}{l}\text { Jacob et al., } \\
2012\end{array}$ & 6 & $12-14$ & $0(0 \%)$ & $4(67 \%)$ & $2(33 \%)$ & $5(83 \%)$ & & $1(17 \%)$ \\
\hline $\begin{array}{l}\text { Moon et al., } \\
2014^{17}\end{array}$ & 14 & $\begin{array}{l}13.2 \\
(12-15)\end{array}$ & $3(21 \%)$ & $8(57 \%)$ & $3(21 \%)$ & $7(50 \%)$ & $5(36 \%)$ & $1(6 \%)$ \\
\hline $\begin{array}{l}\text { Wilkinson et } \\
\text { al., } 2011^{10}\end{array}$ & 6 & $12.5-13$ & $1(17 \%)$ & $5(83 \%)$ & $0(0 \%)$ & $3(50 \%)$ & $2(33 \%)$ & $1(17 \%)$ \\
\hline $\begin{array}{l}\text { Hasegawa et } \\
\text { al., } 2015\end{array}$ & 42 & 12 & $8(19 \%)$ & $\begin{array}{l}29 \\
(69 \%)\end{array}$ & $5(12 \%)$ & $23(55 \%)$ & $19(45 \%)$ & $1(2 \%)$ \\
\hline
\end{tabular}




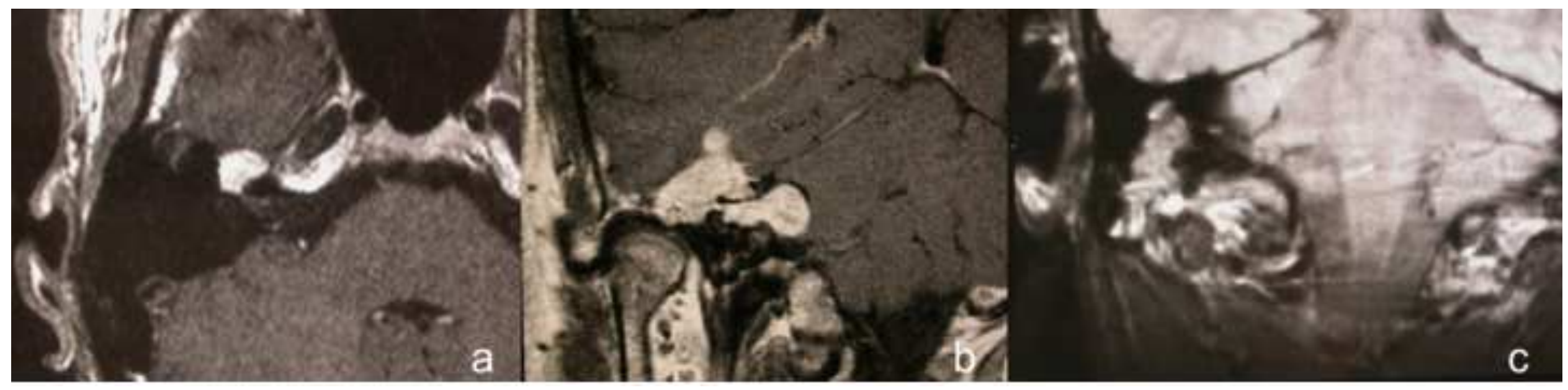




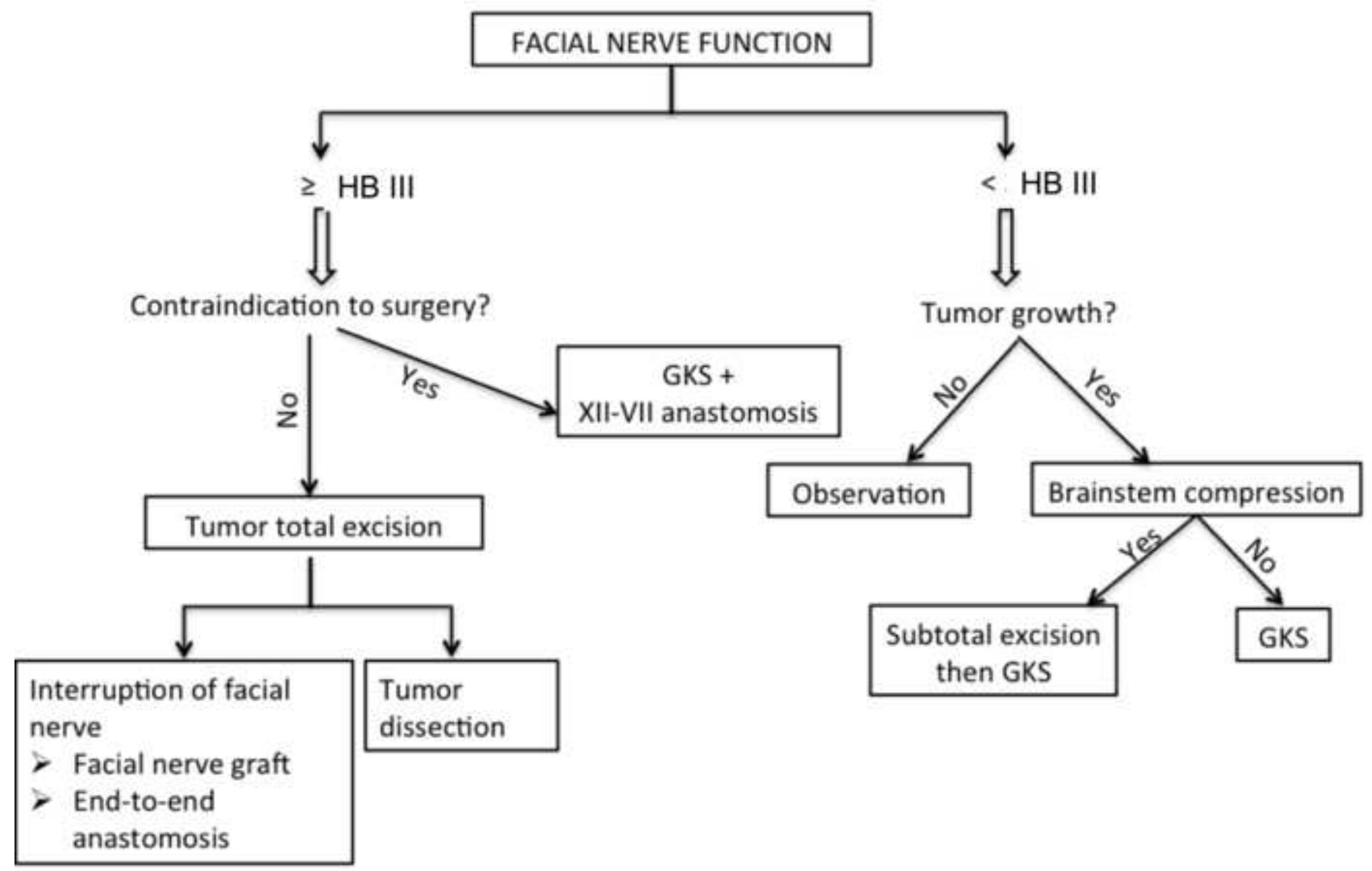

